\title{
Un año de gestión ambiental del gobierno de Flores
}

Un año de gestión ambiental del gobierno de Flores

El desempeño del primer año de gobiemo de Francisco Flores en lo que se refiere a los problemas ambientales que agobian a toda la población, y en forma particular a la mayoría más vulnerable y desprotegida, debe evaluarse considerando los antecedentes de la gestión ambiental gubernamental de los dos períodos anteriores de ARENA y las propuestas ambientales descritas en la "nueva alianza".

Las evaluaciones críticas al desempeño de la actual Ministra del Medio Ambiente o del Ministerio del Medio Ambiente y de los Recursos Naturales (MARN) como institución, deberían interpretarse a partir de la concepción de su creación. En este sentido, el Ministerio es el coordinador de la gestión ambiental del Estado y las direcciones superiores de las instituciones públicas son las que deben - de acuerdo a su competencia- implementar, ejecutar y dar seguimiento a la gestión ambiental'. Por lo que una evaluación desfavorable o favorable de la gestión ambiental, no sólo le compete al Ministerio, sino por igual a todas las instituciones del sector público: ministerios, alcaldías e instituciones autónomas.

Justamente uno de los temores que se tenían con la creación del Ministerio del Medio Ambiente y de los Recursos Naturales es que el apoyo polí- tico es débil, resultado de una situación coyuntural y no del convencimiento de que la gestión ambiental debe ser una parte integral y fundamental de la gestión gubernamental. A esto hay que añadir que el Ministerio nació con un legado institucional frágil, sin un marco legal, en donde la población creó muchas expectativas sobre su desempeño y con la percepción de algunos políticos de que con su creación, la solución de los problemas ambientales se podían delegar en él y, por tanto, desligarse de las propias responsabilidades.

En todo caso, la creación del Ministerio del Medio Ambiente por Decreto Ejecutivo del 16 de mayo de 1997 y la aprobación de la Ley del Medio Ambiente, el 2 de marzo de 1998, son los acontecimientos más relevantes sucedidos en los últimos años en El Salvador, respecto a la construcción de un marco institucional y legal para la protección, conservación y mejoramiento del medio ambiente. La fragilidad institucional la hereda el Ministerio de su antecesor, la Secretaria Ejecutiva del Medio Ambiente.

\section{La Secretaría Ejecutiva del Medio Ambiente (1990-1997)}

El origen de la Secretaría Ejecutiva del Medio Ambiente se encuentra en una iniciativa regional de la AID, que tenía como uno de sus elementos la creación de un Consejo Nacional del Medio

1. Ver Artículos 6 y 7, Sistema de gestión del medio ambiente, Ley del Medio ambiente Ministerio del Medio Ambiente y de los Recursos Naturales. 
Ambiente (CONAMA) en cada país de la región ${ }^{2}$. En 1990, durante el gobierno del presidente Cristiani, se creó el CONAMA, cuya misión era velar por la óptima y racional utilización de los recursos naturales, el control de la contaminación y el establecimiento del equilibrio ecológico. Para ello se le facultó para proponer políticas y estrategias; y se creó, en 1991, la Secretaría como la unidad responsable de coordinar y velar por el comportamiento de las políticas y estrategias emanadas del CONAMA. Al principio, la Secretaría se ubicó orgánicamente en el Ministerio de Agricultura, aunque funcionalmente dependía del CONAMA. El pobre desempeño del CONAMA, entre los años de 1991 a 1994, evidenció que esta institución no funcionaba y que no pudo cumplir con el papel que se le había encomendado". La Secretaría se convierte, así, en ese período -dadas las características del funcionario encargado de la cartera-, en un gestor de recursos externos y en el interlocutor ambiental del gobierno ${ }^{4}$, que no se sentía cómodo con este nuevo rol que lo obligan a jugar ante los organismos internacionales. Su idea era coordinar y vigilar la implementación de las políticas ambientales pretendidas con su creación.

El presidente Calderón Sol, en 1994, cambió al Director Ejecutivo de la Secretaría y esta fue reorganizada, aunque permaneció adscrita al $\mathrm{Mi}$ nisterio de Agricultura y Ganadería. Durante este período, se retiró de la institución una gran parte del equipo de técnicos de alto nivel. Posteriormente se decidió que la Secretaría debía pasar del Ministerio de Agricultura y Ganadería al Ministerio de Planificación y de Desarrollo, luego se nombró un nuevo Director Ejecutivo, se volvió a reestructurar la organización y se produjo un movimiento de técnicos, todo ello con la finalidad de asistir en la formulación de las políticas y en la toma de decisiones para incluir la dimensión ambiental en las diferentes actividades que realizara el gobierno. Sin embargo, el presidente Calderón Sol consideró que no debía haber un ente centralizado que planificara las acciones de su gobierno y, por tanto, disolvió el Ministerio de Planificación y Desarrollo. Asimismo se vio en la necesidad de reubicar a la Secretaría en una nueva casa ${ }^{5}$, el Ministerio de Relaciones Exteriores ${ }^{6}$.

Durante los siete años de vida que tuvo la Secretaría, ésta estuvo a cargo de tres secretarios ejecutivos, quienes provenían de distintos sectores y cuyos intereses, concepciones y estilos de conducción eran distintos ${ }^{7}$. Cada cambio de Secretario Ejecutivo (SE) implicó un proceso traumático para los funcionarios y empleados de la Secretaría, no sólo por los cambios en su estructura orgánica y funcional, sino por la poca estabilidad y alta rotación de sus cuadros técnicos. Por otra parte, fue un proceso frustrante para la sociedad civil, ya que las alianzas que se habían hecho con la Secretaría se disolvieron. De esta manera, estos cambios erosionaron fuertemente la poca legitimidad y credibilidad de la institución, como instancia encargada de la protección ambiental.

A pesar de que, en su corta vida, la Secretaría formó parte de tres diferentes carteras de Estado, su ubicación dentro de la estructura gubemamental no mejoró con los cambios: siempre se le asignó un bajo nivel. Además, en ningún momento se le

2. Ver Prisma, Dinámica de la Degradación Ambiental, 1995, p. 29.

3. El Consejo Nacional del Medio Ambiente fue concebido como un organismo colegiado formado por todos los ministros del gabinete, pero que no funcionó. Podría pensarse que se debió a su tamaño y a la dificultad que tuvo para reunir a todos sus miembros. Sin embargo, la causa que explica su poca capacidad de funcionamiento es la falta de convencimiento - de parte de los ministros- sobre la importancia del tema ambiental y de la necesidad de elaborar e implementar políticas para la protección, el control y la restauración del medio ambiente. A tal grado llegó este desinterés, que todo quedó en manos del Ministerio de Agricultura y Ganadería (MAG), puesto que se veía como algo natural que sólo este Ministerio se interesara, a pesar del discurso manejado por el MAG y la Secretaría Ejecutiva del Medio Ambiente (SEMA) del carácter transectorial de la temática ambiental.

4. Recolectó alrededor de 300 millones de dólares, op. cit., No. 1, p. 30.

5. Se especulaba que se pretendía eliminarla o ubicarla en el Ministerio del Interior.

6. Este cambio se debió, entre otras razones, a que se percibió que su fortaleza continuaba siendo la gestión de recursos externos y la representación del gobicrno en los cónclaves ambientales internacionales. La sociedad civil cuestionó y criticó esta nueva ubicación de la SEMA.

7. Uno provenía de FUSADES, otro de la fracción conservadora de ARENA en la Asamblea Legislativa y el último de AID. 
otorgó un marco legal propio, la autoridad suficiente, el acceso al proceso de toma de decisiones, el presupuesto necesario y el personal suficiente para realizar la labor que la realidad ambiental demandaba en el país.

Esta situación se mantuvo hasta mediados de 1997, cuando el presidente Calderón Sol decidió crear el Ministerio del Medio Ambiente y Recursos Naturales ${ }^{8}$, como se mencionó anteriormente, más por situaciones y presiones coyunturales que por el convencimiento de que el problema ambiental debía ser parte prioritaria de la agenda gubernamental.

\section{El Ministerio del Medio Ambiente y Recursos Naturales entre 1997 y 1999}

Este Ministerio se creó para constituir la instancia del gobierno que tendría la competencia, entre otras, de formular, planificar y ejecutar las políticas en materia de medio ambiente y recursos naturales y de proponer la legislación sobre conservación y uso racional de los recursos naturales y velar por su cumplimiento ${ }^{9}$. No cabe duda de que se le asigna la tarea, aun pendiente, de los distintos gobiernos de ARENA.

El embrión a partir del cual se desarrolló el Ministerio del Medio Ambiente y de los Recursos Naturales fue la Secretaría Ejecutiva del Medio Ambiente. Para ello, al Ministerio le trasladaron los recursos tanto humanos como materiales que tenía la Secretaría. Después se reestructuró nuevamente la organización y se reclutó nuevo personal. En esta reestructuración participó la Comisión de Modernización del Estado y se publicitó, por parte del Ministro"', como el proyecto modelo de modemización del sector público. Durante este período se enfatizó el carácter del Ministerio del Medio Ambiente como ente rector en el ámbito ambiental, cuyas funciones eran nomativas y no ejecutivas.

La aprobación de la LMA, en 1998, enfatizó también la función normativa y de coordinación del Ministerio del Medio Ambiente y de los Recursos Naturales, sobre todo con lo estipulado a la

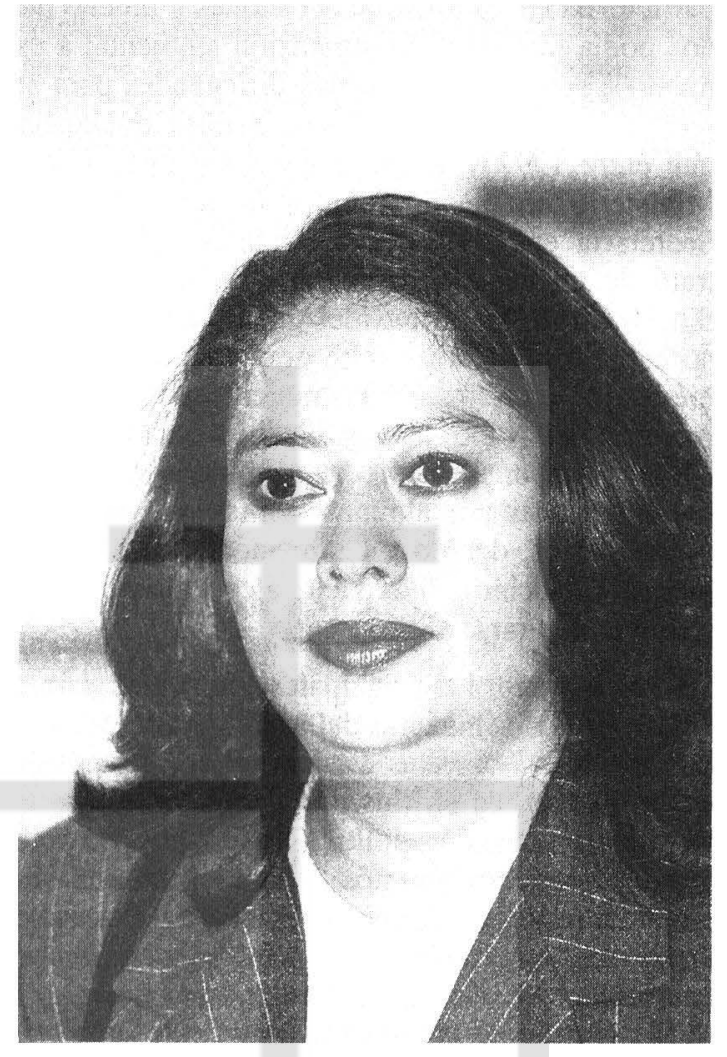

creación del Sistema Nacional del Medio Ambiente (SINAMA), que tendrá como finalidad "establecer, poner en funcionamiento y mantener en las entidades e instituciones del sector público los principios, normas, programación, dirección y coordinación de la gestión ambiental del Estado" "1.

Con la creación del Ministerio del Medio Ambiente y de los Recursos Naturales y la aprobación de la LMA, se suponía que el tema ambiental sería prioritario en la agenda gubernamental, al más alto nivel, y que sería abordado -en forma transversal- por todas las instituciones gubernamentales, en donde el Ministerio del Medio Ambiente y de los Recursos Naturales asumiría la función de coordinación. Sin embargo, esto no sucedió porque el Ministro del Medio Ambiente no sólo no formó parte del gabinete económico $-\mathrm{y}$, por tanto, no

8. Decretos Ejecutivos No. 27 y 30 del 16 de mayo de 1997.

9. Op. cit., No. 6.

10. Se nombra como ministro al primer director ejecutivo de la SEMA.

11. Artículo 6 de la LMA. 
participaba en la toma de decisiones y mucho menos podía introducir la dimensión ambiental a ese nivel-, sino que tenía serias dificultades para ser recibido por el mismo. Estos hechos evidencian que entre 1997 y 1999, la situación que vivió el Ministerio no fue diferente a la que enfrentó la Secretaría entre 1991 y 1997, más bien sólo se trató de un cambio de nombre de la institución. Sin embargo, la actitud del gabinete de gobierno no había cambiado: se trató de una operación cosmética para mejorar su imagen. Las Unidades Ambientales —exigidas por la Ley para formar el Sistema Nacional del Medio Ambiente- más bien fueron creadas por algunas instituciones estatales y ministerios, debido a las presiones de los organismos financieros internacionales y no por el interés de integrarse al Sistema.

Por lo tanto, los principales obstáculos para el desarrollo del Ministerio del Medio Ambiente y de los Recursos Naturales estaban dentro del gobierno y no fuera de él. Sus principales enemigos no ha sido la oposición política ni los grupos ecologistas ni los movimientos sociales, sino sus propios compañeros: los ministros de las otras carteras de Estado. La fortaleza del Ministerio, como era de esperar, fue la misma que tuvo la Secretaría: la gestión de recursos extemos y la interlocución ante los organismos internacionales.

Apoyo al desarrollo del Ministerio del Medio Ambiente y de los Recursos Naturales

Para conocer el interés del gobierno en la protección ambiental, es importante conocer la evolución tanto del presupuesto como la de las plazas del Ministerio del Medio Ambiente, en los últimos tres años ${ }^{12}$. Los dos primeros presupuestos fueron elaborados por el gobierno del presidente Calderón Sol y el último por el presidente Flores. En el Cuadro 1 se observa que, en términos globales, el presupuesto del Ministerio del Medio Ambiente y de los Recursos Naturales se redujo 6.3 por ciento entre 1998 y 1999, y aumentó 24.8 por ciento entre 1999 y 2000 . En términos porcentuales, el presupuesto ha aumentado entre 1998 y 1999 un 15.0 por ciento y entre 1999 y 2000, 21.7 por ciento, aunque todavía es una cantidad muy pequeña ante la magnitud del problema ambiental y las atribuciones y tareas que se esperan del Ministerio. Es evidente que se invierte poco en este Ministerio, ya que al comparar su presupuesto con los presupuestos de otras instituciones del gobiemo, el del Ministerio del Medio Ambiente es uno de los más bajos, lo cual contituye un parámetro de la poca voluntad política que existe para abordar el problema ambiental de una manera comprometida y decidida. Dada la magnitud de la problemática ambiental en el país, es difícil creer que con este presupuesto se pueda invertir en proyectos de prevención y control del deterioro ambiental, sobre todo si los salarios consumen el 59 por ciento del presupuesto y el resto de las instituciones estatales no asumen la responsabilidad que les corresponde desde su especificidad, en la búsqueda de soluciones al problema ambiental.

En relación con el total de plazas, se ha observado un decrecimiento en las mismas en los tres últimos años: el 5.6 por ciento (7) entre 1998 y 1999, y el 9.2 por ciento (11) entre 1999 y 2000, lo cual equivale a una disminución total del 14.3 por ciento (18). Al comparar la cantidad de plazas del Ministerio con la del resto de las instituciones del área de gestión 4, se observa que le corresponden sólo el 0.95 por ciento de las plazas totales, el 21.3 por ciento de las plazas técnicas y $\mathbf{4 6 . 3}$ por ciento de las plazas universitarias.

\section{Cuadro 1}

Presupuesto y plazas en el Ministerio del Medio Ambiente y de los Recursos Naturales

(1998-2000)

\begin{tabular}{lccc}
\hline Rubro & 1998 & 1999 & 2000 \\
\hline $\begin{array}{l}\text { Presupuesto } \\
\text { (en millones de colones) }\end{array}$ & 25.3 & 23.7 & 29.6 \\
\% del presupuesto total & 0.20 & 0.23 & 0.28 \\
Plazas & 126 & 119 & 108 \\
\hline
\end{tabular}

Por otra parte, el Ministerio está incluido dentro del área de gestión 4: Apoyo al desarrollo económico. Dentro de esta área, es la institución que tuvo la menor participación presupuestal en 1999, el 1.31 por ciento. Al compararlo con el 60.8 por

12. Dado que el Ministerio del Medio Ambiente y de los Recursos Naturales (MARN) se abrió en junio de 1997, sólo existe información para los años fiscales de 1998 al 2000. 
ciento de Obras Públicas, se puede dimensionar el desequilibrio en la asignación de fondos.

\section{La gestión del Ministerio del Medio Ambiente y de los Recursos Naturales en el período actual}

A partir de la toma de posesión del presidente Flores, a mediados de 1999 , la nueva Ministra ${ }^{13}$ se propone la tarea de impulsar las líneas estratégicas expresadas en la "nueva alianza"', aunque el presupuesto asignado no indica ningún cambio respecto a la importancia que el gobierno central le atribuye al Ministerio del Medio Ambiente y de los Recursos Naturales.

En la "nueva alianza" se pueden identificar las siguientes líneas estratégicas para revertir el deterioro ambiental: dar prioridad financiera para mejorar, en forma considerable, el acceso al saneamiento básico; iniciar el rescate de los ríos contaminados; crear incentivos que apoyen un proceso de reconversión industrial gradual; apoyar el desarrollo integral y sostenible de las cuencas hidrográficas principales e implementar una política de control de emisiones de gases.

Es claro que no sólo este Ministerio tiene que implementar estas líneas estratégicas. Por lo tanto, en el informe del primer año de gobierno que pronunció Flores ante la Asamblea Legislativa, se esperaba encontrar el grado de avance que se ha logrado en las diferentes líneas estratégicas, como reflejo de la voluntad política de su gobiemo de atender los graves problemas ambientales.

La primera línea estratégica se refleja, en el informe, cuando se menciona que en materia de saneamiento ambiental se ha logrado mejorar la cobertura de letrinización y servicios de agua potable en importantes zonas del país aunque, a diferencia de otros logros mencionados en el informe, no existe un dato cuantitativo de cuantos recursos adicionales se han agregado para comprobar la prioridad financiera. En cuanto al rescate de los ríos contaminados, la creación de incentivos que apoyen un proceso de reconversión industrial gradual, el apoyo del desarrollo integral y sostenible de las cuencas hidrográficas principales y la implementación de una política de control de emisiones de gases, no se hace ninguna mención, lo cual permite inferir que no se ha trabajado en nada relevante durante este primer año. Sin embargo, hay que mencionar que se presentan como logros ambientales un programa de financiamiento para sembrar fincas de café, como solución "práctica y efectiva para evitar la degradación de nuestros recursos naturales", y la creación de 25 nuevas áreas naturales protegidas.

En este primer informe del primer año de gestión, pronunciado por Flores, no se puede identificar con claridad la implementación de las líneas estratégicas establecidas en la "nueva alianza" $y$, con base en esa referencia, se puede considerar que, al cabo de su primer año de gobierno, el grado de avance ha sido muy poco.

Los resultados obtenidos ante las expectativas iniciales siguen siendo, pues, mas bien modestos, y el involucramiento de las diferentes instituciones estatales coordinadas por el Ministerio del Medio Ambiente y de los Recursos Naturales, de acuerdo con lo concebido en la LMA, aún es incipiente; aunque tampoco se esperaba que en un año cambiara la situación, dadas las debilidades y los problemas heredados de los gobiernos anteriores. A esto hay que añadir que la Ministra - seleccionada a partir del proceso establecido por el presidente Flores y su equipo de trabajo- era una persona poca conocida en el medio, lo que, independiente de su capacidad técnica, ha requerido obviamente de un período para que ella pueda conocer y pueda conocerse su estilo de trabajo y su voluntad de ejecutar las acciones correspondientes.

Ante estas circunstancias, no es de extrañarse que en este primer año de gestión, el Ministerio del Medio Ambiente y de los Recursos Naturales sigue siendo percibido - por los diferentes sectores - como una institución de poca incidencia y relevancia, incluyendo al mismo sector estatal. De hecho, aunque la LMA lo requiere, las evaluaciones ambientales estratégicas que las instituciones de la administración pública deben presentar -a efecto de evaluar la repercusión que tienen sus políticas, planes y programas en el medio ambiente-, en general aún no han sido presentadas y las que ya lo hicieron se debe, más bien, al resultado de otro tipo de situaciones. Cabe agregar que tampoco se conocen lineamientos claros para realizarlas.

13. La Dra. Ana María Majano, que proviene del sector energético.

14. La Nueva Alianza, Programa de Gobierno 1999-2004, pp. 27-29. 
El requerimiento para que el Ministerio conceda un permiso ambiental, a través de un proceso de evaluación del impacto ambiental de las actividades, obras y proyectos, constituye uno de los instrumentos -y, quizás, el único que pueda utilizar a corto plazo-, que le permitan al Ministerio ir adquiriendo la relevancia que le corresponde. Este proceso, sin embargo, todavía sigue siendo un laberinto confuso y poco transparente, percibiéndose como un obstáculo más y no como una herramienta de solución de problemas.

En el marco del cumplimiento de la LMA, se pueden seguir citando muchos otros ejemplos, en donde las acciones necesarias aún no se han realizado y, en algunos casos, ni siquiera se han definido.

No obstante, se debe reconocer que han habido algunas señales que pueden abrir el camino para que la función fundamental del Ministerio y de la gestión ambiental, dentro de la gestión gubernamental, se reconozca con la importancia que se merece. Así, por primera vez en ocho años, desde que se creó la Secretaría, se le atribuye a la $\mathrm{Mi}$ nistra del Medio Ambiente y de los Recursos Naturales la función de coordinadora de la Comisión de Desarrollo Territorial, en la cual se participa —al más alto nivel y en forma transversalcon las otras carteras de Estado en la toma de decisiones.

La aprobación de la mayor parte de reglamentos requeridos por la LMA también pueden considerarse como un cambio en la dirección correcta, aunque los obstáculos para su operativización aún no han sido removidos.

Precisamente en esto reside el mayor reto para la gestión de la Ministra actual, es decir, convertir al Ministerio del Medio Ambiente y de los Recursos Naturales en lo que le manda la LMA: en una institución coordinadora de la gestión ambiental estatal. 